and scarcely any discharge is to be obtained from the cavity of the wound, even with firm manual pressure. The part is then dressed anew and left alone for eight or ten days. This method of dressing I have now adopted as my routine practice in the case of large wounds, and I certainly think that it is more conducive to healing by primary union than any other which I have seen practised. In the case of small wounds I still rely on pressure, without provision for drainage.

The hooks have been made for me by Messrs. Weiss and Son, King-street, Manchester.

To make a self-retaining drainage-tube, as for an empyema, eat a ring one-sixth of an inch wide off the end of a largesized drainage-tube; cut it across into halves (Fig. 2), and

Frg. 2.

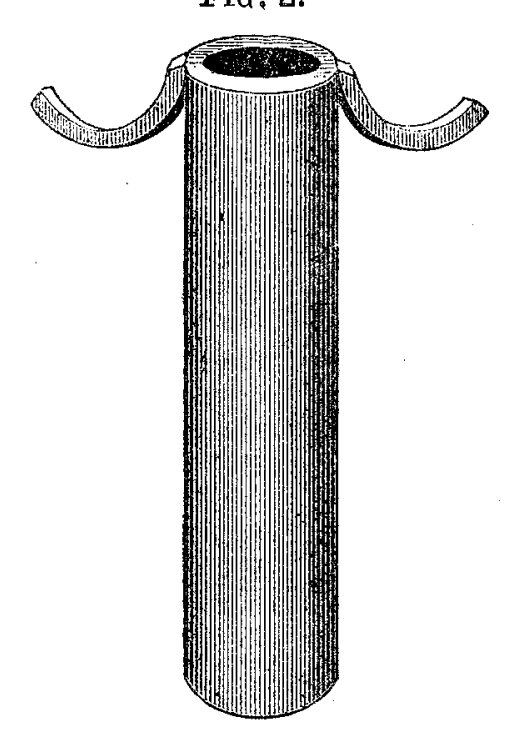

then stitch with silver wire the end of one half on each side of the tube, close to the orifice, the convexity of the ring being applied to the side of the tube. When inserted in a cavity it is thus retained from falling out, in the same way as the winged self-retaining catheter.

Manchester.

\section{SPINAL THROMBOSIS AND HÆMORRHAGE DUE TO SYPHILITIC DISEASE OF THE VESSELS.}

BY R. T. WILLLaMSON, M.D., M.R.C.P. Lond., MLDIGAT REGISTRAR, ROYAL INHIRMARY, AND ASSYSTANT IN MEDICINE, OWENS COLLEGE, MANCHESTER.

THOUGH hæmorrhage and thrombosis are so cornmon in the brain, these conditions have been very rarely met with (pathologically) in the spinal cord, and until recently but little attention has been paid to thrombosis in the spinal bloodvessels. From the frequency and importance of cerebral thrombosis one would expect that thrombosis in the spinal vessels would also play an important part in diseases of the spinal cord; but as yet the pathological evidence on this point is very small. Hence the pathological changes in the case described below appear to be worthy of record. I am indebted to the kindness of Dr. Steell for the opportunity of making the pathological examination.

The patient was a man aged twenty-eight, who was admitted under the care of Dr. Graham Steell at the Manchester Royal Infirmary on Sept. 22ud, 1893. About one month previous to admission the patient began to suffer from pains in the back, under the left scapula. There was sometimes pain under the right scapula; sometimes pain extended round the left axillary region, and as far forwards as the cardiac region. The pain was not severe, but continued more or less until the onset of paralysis. On Sept. 20th he first noticed some difficulty in passing his urine, but at that time he could walk quite well and had no pain. In the evening his gait was unsteady. Farly in the night, after going to bed, he felt a desire to micturate. He got up, but found that he was quite unable to pass his urine. He was able to walk fairly well, and went downstairs for a short time. He then returned to bed and fell asleep. On awaking in the norning he found that both legs were paralysed. He could just "put the legs together," but could not stand. He stated that there was loss of feeling in the legs. There was no pain anywhere and no girdle sensation. There had been loss of control over the rectum and retention of urine ever since the night of Sept. 20th. A catheter had been passed twice daily. There was no history of injury to the back, but there was a history of alcoholism and syphilis. Two years previously he had had a chancre followed by sore-throat and falling off of the hair, for which he was treated by a medical man with iodide of potassium.

On Sept. 25tb both legs were completely paralysed; the limbs were flaccid. Knee-jerks, ankle clonus, and cremasteric, abdominal, and epigastric reflexes were absent on both sides. Very slight plantar reflexes were obtained. There was no paralysis of the upper limbs, intercostal muscles, or diaphragm. There was loss of sensation to tactile and painful impressions (to the head and point of a pin) on the legs and trunk as high as the sixth intercostal space. In this interspace there was impaired sensation, but in the fifth intercostal space, and in all parts above, the sensation to tactile and painful impressions was good. There was no band of hyperæesthesia, no girdle sensation, and no spinal curvature. There was complete loss of control over the rectum and retention of urine. The rate of respiration was 36 per minute. There was a large amount of expectoration, and submucous râles and rhonchi were heard all over the chest. Nothing of importance was detected in the other organs. The urine contained pus and a large amount of blood.

On Oct 3rd anæsthesia (to the head and point of the pin) extended as high as the sixth rib. There was now a zone of hyperæsthesia in the fifth interspace. The kneejerks were absent. The urine contained blood and pus. The mental condition was very dull. On the 4th there was profuse diarrhoa and abundant expectoration. After admission rigors occurred once or twice daily, and the temperature was remittent or intermittent, high in the evening (on two occasions reaching $103^{\circ} \mathrm{F}$.), lower or normal in the morning. A bedsore developed on the right buttock. The motions were passed involuntarily, and the retention of urine continued. The area of anesthesia remained unaltered. The patient continued in much the same condition until his death on the 5 th. Death appeared to be due to the pyæmic condition.

Necropsy (abstract).-Over the sacrum and right gluteal region were bedsores, and an old cicatrix was found on the glans penis. The brain was congested. The lateral ventricles contained a considerable amount of clear serous fluid. There were no signs of tubercle, syphilis, or other gross lesion. The lungs were congested and œdematous, bat crepitant in all parts. The heart weighed $11 \mathrm{oz}$. , and the valves were normal. The peritoneum was normal; the gastro-intestinal tract was congested. The liver weighed $4 \mathrm{lb}$. $4 \mathrm{oz}$., and was slightly enlarged. The spleen was enlarged slightly and weighed $10 \mathrm{oz}$. The kidneys presented well-marked signs of acute nephritis. There was also hæmorrhagic and suppurative pyelitis on both sides. The ureters were acutely inflamed and there was acute suppurative cystitis. The spinal cord showed no evidences of softening at any part, and was very firm and in exceed: ingly good condition. The meninges vere congested, but no other naked-eye changes were detected on the surface of the cord. On section, about the midale dorsal region a hæmorrhage was found, occupying the whole of the grey matter of the cord on the left side. Scrapings from the cut surface of this part were examined in a 1 per cent. solution of osmic acid at the time of the necropsy, but no compound granular cells could be detected microscopically. The cord was not softened in the region of the hæmorrhage. No attempt was made to deterwine the limits of the lesion at the necropsy ; the cord was placed to harden in Müller's fluid. After hardening, a number of transverse divisions were made in the dorsal region, and on naked-eye examination a large hæmorrhage, dark-brownish-red in colour, was found in the grey matter of the left side of the cord, about the mid-dorsal region. The vertical extent was about one inch and three-quarters (downwards from the mid-dorsal region). At both the upper and lower parts the hæmorrhage was limited to a small streak in the posterior horn (left). About the centre of the lesion the hæmorrhage occupied the whole of the grey matter of the left side, and extended across the grey commissure into the central part of the grey matter of the right side. For one inch below the inferior part of the hæmorrhage a few white points were seen scattered through the white matter of both sides; also a few white streaks were geen in the white 
matter in some sections. The same condition was met with for about two inches above the highest part of the hæmor rhage. In the cervical and upper dorsal regions (above the lesion) the posterior columns presented the naked-eye appearances of ascending degeneration-i.e., these parts were paler than the rest of the white matter. To the naked eye there did not appear to be any descending degeneration below the lesion. The whole of the affected part of the cord (i.e., at the seat of hrmorrhage), was cut into sections (celloidin method), and every third examined. Altogether some hundreds of sections were obtained. Numerous sections were also taken a little above and a little below the seat of hæmorrhage, and in the cervical and lumbar regions. The sections were stained with logwood, aniline blue black, logwood and eosin, and according to Weigert's method.

Microsoopical examination showed that in the parts which, to the naked eye, appeared dark red (hæmorrhagic), the tissues were infiltrated and replaced by a mass of red blood corpuscles. At the highest part of the lesion, the hæmorrhage was limited to a small streak in the left posterior horn of grey matter; at a lower level it extended to the outer part of the grey matter (Fig. 1); a little lower it became more extensive, occupied the whole of the grey matter, and spread in irregular patches to the white matter of the left half of the cord (Fig. 2). Near the middle of the

FIGs 1-4 vertical extent of the lesion the hæmorrhage FIGs. 1-4. extended to the grey commissure, and then over to the grey matter of the right half
of the cord, but never became so extenof the cord, but never became so extenthe left, and occupied only the centre of the right grey matter (Fig. 3). At a lower level the hamorrhage was confined to the grey matter of the left side (Fig. 4), and at the lowest part only a small streak of hæmorrhage was seen in the posterior horn. A few very small patches of hæmorrhage, chiefly around oilated vessels, were scattered irregularly in the white matter. Next to the bremorrhages the most striking feature of the sections of the cord was the great number of enormously dilated bloodvessels, especially in the grey matter and the adjacent white matter of the left side at the seat of the tæmorrhage. Some of these vessels were equal in diameter to the breadth of the grey commissure. Dilated vessels were seen in the grey matter, for a short distance above and below the hremorrhage and also in the grey matter of the right side of the cord: but the most marked dilatation was seen on the left side in the region of the hæmorDiagrams of the rhage. At one point, however, where the spinal cord. rhage. At one point, however, where the
Parts sharled $=$ bamorrhage was greatest-i.e., where it seat of hæmox- occupied almost the whole of the grey rhage. matter of the left side - only a few of these dilated vessels were seen. The vessels were packed full of red corpuscles, and very many were thrombosed. In the interior of these thrombosed vessels, close to the vessel wall, was an irregular layer of granular-looking substance (stained pink with eosin), containing many fine fibres, nuclei, and nucleated cells, whilst red blood corpuscles, with leucceytes, were se en nearer the centre. In some of the vessels this new-formed tissue occupied more tban half of the lumen, and extended in an irregular manner to the centre. (Fig. 5.) The walls of these vessels were thickly covered with nuclei, and there was well-marked perivascular cell infiltration, the amount varying at different parts. A large number of these thrombosed vessels were surrounded by hæmorrhage. In a good number of sections, the anterior medial artery was obstructed by a thrombus. In a few sections, the central canal was surrounded by a zone of tissue crowded with nuclei ; in others it was surrounded by hæmorrhage. Scattered irregularly in the white matter, in some of the sections, a few small patches were seen in which the interstitial tissue was a little in excess and its nuclei increased in number and size. As already mentioned, for two inches above and about one inch below the hæmorrhage, a few irregularly distributed white points and streaks were seen on the cut surface of the hardened cord, and microscopical examination showed that these were due to dilated vessels with marked perivascular cell infiltration. At no part of the cord were any compound granular cells to be seen; and the inflammatory changesexcess of nuclei and cell infiltration-were always just around the vessels. In all, even the upper cervical and lumbar regrions,

Fit. 5.

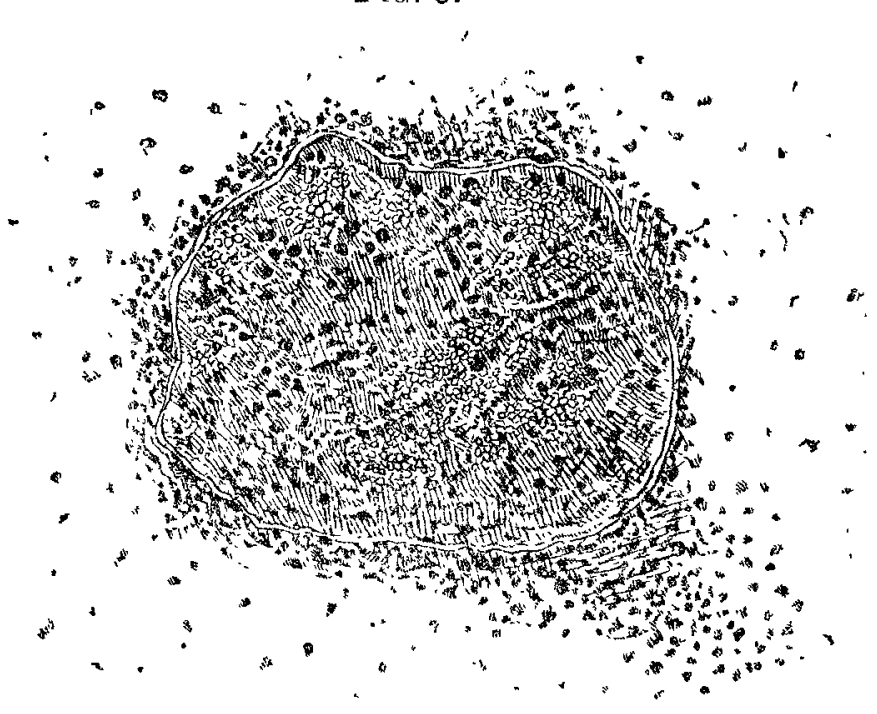

Greatly dilated and thrombosed vessel in the grey matter of the cord.

there were distinct changes in the meninges. These consisted of infiltration with round cells and marked vascular changes. The cell infiltration was only slight in the cervical and lumbar

FIG. 6.

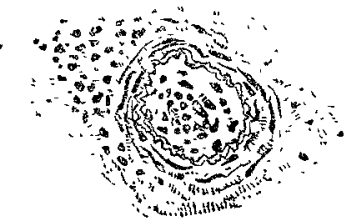

Small artery showing well-marked endarteritis.

regions. The vessels of the meninges and of the cord showed distinct syphilitic changes ; they were best marked, however. in the meninges. The walls of many vessels were greatly

Frg. 7 .

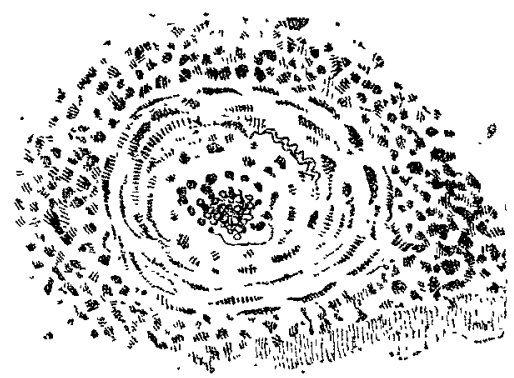

Meningeal artery showing endarteritis and periarteritis.

thickened. In many there was well-marked endarteritis-sometimes so extensive that the lumen was almost obliteratedand in a few arteries no lumen could be detected. Some of

FIG. 8.

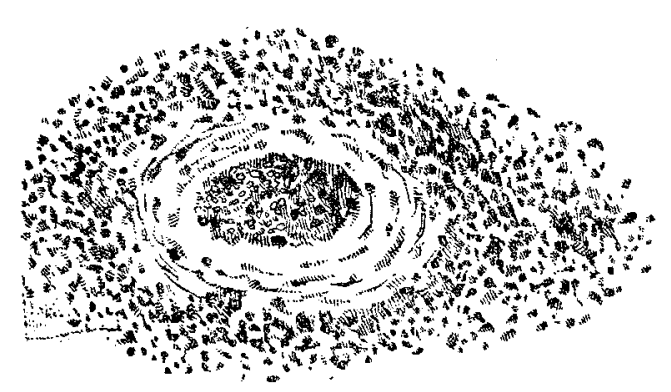

Meningeal vein showing endophlebitis, periphlebitis, and thrombosis.

the arteries were obstructed by a thrombus. The adventitia was greatly thickened and infiltrated with round cells; there 
was also perivascular cell infiltration. Similar changes were met with in many of the veins-endophlebitis, periphlebitis, thrombosis. (Figs. 6, 7, 8.)

Pathological diagnosis.-Syphilitic disease of vessels (endarteritis, periarteritis, endophlebitis, periphlebitis); thrombosis; hæmatomyelia; leptomeningitis.

The onset of the symptoms in the case recorded above was not quite so sudden as is usual in so-called primary spinal larmorrhage. The slight pain in the back for a month previous to the paralysis, the retention of urine, and the slight unsteadiness in gait for some hours previous to the actual paraplegia, together with the history of syphilis, appeared, during life, to be points against a primary hæmorrhage, and more in favour of a diagnosis of very acute myelitis. But the microscopical examination showed clearly that the primary change was syphilitic disease of the vessels, and that this was followed by thrombosis and hæmorrhage. There can be no doubt that the thrombosis of vessels occurred before the hemorrbage and not as a result of it, because (1) though the thrombosis of the vessels of the grey matter was most marked in the dorsal region at the seat of hæmorrhage, and for a short distance above and below, yet thrombosed vessels were found in the meninges far away from the hæmorrhage, in the upper cervical and lumbar regions; (2) many of the thrombi were clearly of older date than the hæmorrhage; (3) there were marked vascular changes which alone would account for the thrombosis; and (4) the blood corpuscles in some of the thrombosed vessels were altered in shape, and some were broken down into granules, whilst the corpuscles in the hæmorrhage around were unaltered, and evidently the hemorrhage was more recent than the thrombus.

The inflammatory changes-excess of nuclei and cell iniltration-were, as a rule, just around dilated vessels.

'Though spinal thrombosis has been suggested by many writers as a primary cause of paraplegia of sudden onset in syphilitic patients, hitherto the pathological evidence Jas been slight. The pathological examination of the above case shows clearly that, in a syphilitic patient, varaplegia of sudden onset (with anresthesia and bladder and rectal symptoms) was due to thrombosis in diseased ressels followed by hæmorrhage. The case is also of interest inasmuch as syphilitic disease of vessels and thrombosis are not usually included among the causes of brematomyelia in the descriptions of this disease.

Oxford-road, Manchester.

\section{PHTHISICAL FAMILY HISTORY IN RELA- TION TO LIFE ASSURANCE.}

BY THOS. GLOVER LYON, M.A.CAMB., M.D. LOND.,

GENTOR ASISTANT PHYYSTCIAN, VTOTORYA PARK HOSPITAL FOR CHEST DSEASES; MEDICAL OFFICER MUTUAL LIFE OFFICL; FORMERLY
MATHEMATICAL SCHOLAR, EMMAYUEL COLLEGE, CAMBRIDGE.

Turs important subject has long exercised the minds of life assurance medical officers. In former years extensive Investigations were made by several authorities into the records of various hospitals, but a little consideration is sufficient to convince one that the data furnished from such sources is insufficient to form the basis for the solution of the problem. What is wanted in such investigations is the number of deaths occurring amongst a certain number of persons at risk; these factors cannot be obtained from medical records. The subject was next approached in another way by several assurance offices, notably by the Matual Life Assurance Company of New York. In these cases it was scientifically conducted upon actuarial principles by the joint action of actuary and medical officer, but was limited to ascertaining the experience of the officers amongst lives which had given a family history of consumption "and had died of consumption." It will be erident that this method does not cover the whole ground. Persons who have a phthisical family history may well, and probably are, more liable to die than others from many causes other than phthisis, more especially chest affections. The results of these inquiries was to confirm the medical impression that hereditary consumptives are inferior lives, taking for granted that such a family taint does not give immunity from other dangers. The first attempt to investigate the subject under consideration by a complete method was, I believe, undertaken by Mr. Manly and myself during the gears 1890 and 1891, and was bused upon the records of the
Mutual Life of London. In the appended remarks will be found a summary of the conclusions arrived at. Before giving the results of this inquiry it would be useful to consider certain points, as regards the applicant himself, generally considered to be important in the selection of lives, who may be suspected of being specially liable to consumption. They are : (1) physique ; (2) conditions of life ; (3) age. Without assuming the existence of a recognisable consumptive type, there is no doubt that delicate persons, more especially those who are weak in the chest, are specially liable to phthisis. The importance, therefore, of rejecting applicants of such constitutions will be evident. The reports of some offices appear to show that the weight of the applicant is an indication of his power of resisting the disease, those above the average weight being less liable than those below it. I believe that reliance upon the general impression of the medical examiner is preferable to trusting to any rules of this kind. The necessity of rejecting applicants engaged in pursuits whose conditions favour in them the production of phthisis need not be insisted upon.

Table shoning the Mortality from Phthisis in England and Wales between $18 \% 1$ and 1880, according to the Registrar. General; also the Mortality from Consumption in Three Life Offices-the Policies at Risk extending over 392,66is Tears of Life.

\begin{tabular}{|c|c|c|c|}
\hline \multirow{3}{*}{ Age at death. } & \multicolumn{3}{|c|}{ Deaths per mille per annum. } \\
\hline & \multicolumn{2}{|c|}{ Registrar-General. } & \multirow[t]{2}{*}{ Three offices. } \\
\hline & Males. & Females. & \\
\hline $20-24$ & $3 \cdot 09$ & $3 \cdot 14$ & $2 \cdot 0$ \\
\hline $25-34$ & $3 \cdot 70$ & $3 \cdot 54$ & $2 \cdot 29$ \\
\hline $35-44$ & $4 \cdot 12$ & $3 \cdot 34$ & $2 \cdot 28$ \\
\hline $45-54$ & $3 \cdot 86$ & $2 \cdot 46$ & $1 \cdot 93$ \\
\hline $55-64$ & $3 \cdot 19$ & $1 \cdot 78$ & $1 \cdot 79$ \\
\hline $20-64$ & $3 \cdot 45$ & $2 \cdot 91$ & $2 \cdot 06$ \\
\hline
\end{tabular}

From these tables it will be seen that the highest mortality from consumption in males, according to the RegistrarGeneral, is between thirty-five and forty-five, decreasing only slightly as age advances, so that the percentage of deaths of those living between fifty-five and sixty-four is bigher than that between twenty and twenty-four. This variation in mortality according to age is in great divergence from the impression in general acceptance. In New York the registered mortality from phthisis continues to increase with age until the end of life. In view of the well-known inaccuracy of registration in the British Isles (so well brought out recently by $\mathrm{Mr}$. King and Dr. Newsholme with respect to cancer) it is open to question whether the diminution in the mortality from phthisis as age advances registered at home may not be due to errors of diagnosis consequent upon hesitation to regard as phthisical cases occurring in advanced life. It will be observed that there is no rise in the mortality amongst females corresponding to the climateric, and that the mortality from phthisis amongst insured lives varies much in the same way, according to age, as in the population generally. It has often been contended that the danger from consump. tion is much diminished after forty years of age, but in the face of these figures this must be taken with great reserve. The fact being that the danger from consumption diminishes only slightly with age absolutely, but relatively to the danger from other diseases, it diminishes quickly after about fortyfive. This is important from an insurance point of view, as showing that consumption, speaking generally, becomes of less consequence as age advances. Our real concern is, how. ever, with the extra risk alleged to attend a family history of consumption. Now the mere fact that a man has survived to the age of forty and is still in robust health, is evidence in itself that he was not born with a special liability to the disease. Indeed, I do not believe that, as a rule, much harm would be done by taking all applicants who had arrived at forty years of age, and who still remained of robust constitution, at ordinary rates. Deaths occurring from phthisis after forty-five should be regarded as accidental, and not due to any special susceptibility to the disease. But whether this view be the correct one or not can be determined only by actuarial investigation.

A reference to the table given above shows that during 